\title{
Bored by bothering? A cost-value approach to pandemic boredom
}

\author{
Corinna S. Martarelli (i) ${ }^{1 \times}$, Wanja Wolff ${ }^{2,3} \&$ Maik Bieleke ${ }^{2}$
}

In an effort to mitigate the impact of the COVID-19 pandemic, countries around the world have employed non-pharmaceutical containment measures. The effectiveness of such mitigation efforts relies on individual compliance (e.g., avoiding to travel or to gather). Crucially, adhering to the required behavioral recommendations places substantial burdens on those who are asked to follow them. One particularly likely outcome of adherence should be the experience of boredom. Thus, people might get bored by bothering. Drawing from research and theorizing on reward-based decision making, we conducted a high-powered study ( $N=1553$ US participants) to investigate whether the value and effort people ascribe to adherence to containment measures directly and indirectly (i.e., mediated by adherence) affects their experience of boredom. As expected, structural equation modeling revealed that high value and low effort predicted compliance with behavioral recommendations. Moreover, higher compliance was linked to more boredom, meaning that high value and low effort increased boredom via compliance. In contrast, high value and low effort had direct effects on boredom in the opposite direction (i.e., decreasing boredom). Attesting to their robustness and generalizability, these findings held for both prospective (with respect to upcoming winter holidays) and retrospective behavior (with respect to previous thanksgiving holidays), across US states, which had or had not enforced behavioral restrictions, individual differences in boredom proneness, and demographic variables. Taken together, our results provide evidence that people can indeed get bored by bothering: Complying with nonpharmacological containment measures like avoiding to travel and to gather can come at the cost of getting bored, an experience that was strongly linked to negative affect in our study.

\footnotetext{
${ }^{1}$ Faculty of Psychology, UniDistance Suisse, Brig, Switzerland. ${ }^{2}$ Department of Sport Science, University of Konstanz, Konstanz, Germany. ${ }^{3}$ Department of

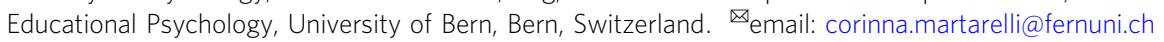




\section{Introduction}

t the time of this research (December 2020), the coronavirus disease (COVID-19) was imposing substantial restrictions on the way people were living. As an efficient therapeutic cure was still lacking and vaccination programs had not yet started, many countries resorted to non-pharmaceutical containment measures, including the reduction of physical contact, the suspension of gatherings, the closing of borders, among others. Mathematical modeling of the COVID-19 transmission dynamics has demonstrated that these measures can be effective in limiting the spread of the virus (e.g., Kucharski et al., 2020; Prem et al., 2020). However, for these measures to be effective, individual compliance is critical. One psychological construct that has been proposed to affect compliance is boredom (Martarelli and Wolff, 2020) and research suggests that boredom proneness (i.e., a general tendency to experience boredom more frequently and more intensely, Farmer and Sundberg, 1986) undermines people's compliance with containment measures (Bieleke et al., 2021; Boylan et al., 2020; Wolff et al., 2020). However, while research indicates that trait-like boredom proneness might threaten adherence to containment measures, less is known about whether adherence to containment measures can in turn elicit state boredom. Investigating whether compliance with containment measures is a determinant of state boredom is the main goal of this study.

\section{Pandemic boredom: the role of perceived value and effort}

Several theories of boredom have been proposed (for a comprehensive review see Westgate and Wilson, 2018) and despite disagreement whether boredom is one or many (Elpidorou, 2021), researchers agree that boredom is an aversive experience of wanting but failing to satisfy the want (Eastwood et al., 2012; Danckert et al., 2018). The Meaning and Attentional Components (MAC) model (Westgate and Wilson, 2018) as well as the Control-Value Theory (CVT) of achievement emotions (Pekrun, 2006; Pekrun et al., 2010) are both compatible with the idea that perceived value and effort play an important role in the experience of boredom. Indeed, boredom might occur when (1) there is nothing meaningful available to do (see also Fahlman et al., 2009; van Tilburg and Igou, 2012) and (2) when one experiences a high degree of mental effort in trying to engage with an ongoing activity (understimulation or overstimulation, see also Bieleke et al., 2021; Eastwood et al., 2012). First, a perceived lack of meaning has been highlighted as an important determinant of the experience of boredom (e.g., Pekrun, 2006; Fahlman et al., 2009; Pekrun et al., 2010). Van Tilburg and Igou (2013) proposed that individuals take into account two aspects when evaluating the meaningfulness of behavior: The value of the superordinate goal and the usefulness of the actual behavior to reach that goal (see also Westgate and Wilson, 2018). Second, being trapped in a boring situation with constrained opportunities to engage in alternative, rewarding activities should be accompanied by feelings of mental effort (e.g., Eastwood et al., 2012). But why is being bored accompanied by the sense of effort? One likely answer comes from recent functional accounts of boredom and its interplay with self-control (e.g., Bieleke and Wolff, 2021; Wolff and Martarelli, 2020), in which boredom is understood to act as a signal to engage with something else that is more rewarding (e.g., Bench and Lench, 2013, 2019; Kurzban et al., 2013; Elpidorou, 2014, 2018; Danckert, 2019). More precisely, boredom signals that an activity is decreasing in value and that the available resources might be better spent engaging in something else. In turn, choosing (or being forced) to stay engaged with an activity that is boring requires self-control, the application of which creates the sense of effort (e.g., Shenhav et al., 2017).
Boredom has been highlighted as a potential consequence of prolonged adherence to containment measures before (DroitVolet et al., 2020; Yan et al., 2021). After almost one year of behavioral restrictions due to the COVID-19 pandemic, it is conceivable that changes in perceived value and in perceived effort give rise to boredom during the pandemic: The limited set of available activities has likely become monotonous and uninteresting, and compliance might likewise feel difficult and exhausting. Indeed, media outlets have coined the term "pandemic fatigue" (e.g., Badre, 2021) and have started to focus on the potential rise of boredom during the pandemic (e.g., Ehl, 2021). A time where adhering to containment measures might feel particularly hard and void of meaning are the thanksgiving and winter holidays. While these holidays traditionally entail visiting loved ones, travel and gathering restrictions substantially limit the degree to which it is safe and legal to do so. Staying home alone during this time and complying with restrictions therefore likely requires additional effort and severely tests the degree to which one perceives these measures as being valuable (particularly in contrast with what one is missing out on).

\section{The present study}

When data were collected for the present study, there was a rise of COVID-19 infections, hospitalizations, and deaths across the world. Countries were facing the coronavirus second wave, and there were no therapeutic agents available. Thus, several containment measures restricting the freedom of movement (e.g., closing of workplaces, schools, and borders, among others) used during the coronavirus first wave were again employed by governments. Countries were in the process of gradually tightening the containment measures. Restrictions on freedom of movement have been suggested to amplify the experience of boredom in boredom prone individuals (Martarelli and Wolff, 2020). Indeed, behavioral alternatives are reduced when containment measures come into force, which should increase and intensify the experience of boredom.

In line with this idea, we examined experienced and forecasted pandemic boredom as a result of avoiding to travel and to gather with others (Owens and Baker, 2020) during the past thanksgiving (retrospective) and intending to do so during the upcoming winter holidays (prospective) in the US, respectively. Including both retrospective and prospective behaviors allows us to test the same model at two timepoints and serves as a robustness check. We further investigated pandemic boredom by adopting a cost-value approach to behavior and boredom. A lack of meaning and value as well as effort-related costs are known to prompt the experience of boredom (Eastwood et al., 2012; Westgate and Wilson, 2018). We thus expected boredom to be experienced especially when low value and high effort are ascribed to avoiding traveling and gathering (i.e., direct effects of value and effort on boredom). However, people should also be less likely to avoid traveling and gathering if they ascribe low value and high effort to these measures, which then should lead to reduced boredom (i.e., indirect effects of value and effort on boredom). Note that the direct and indirect effects should be inverted: While low value and high effort increase boredom directly, they also reduce boredom by instigating non-compliance with behavioral recommendations. Which of these two effects ultimately determines the experience of boredom is an open question that we address in the present research. To scrutinize the impact of the pandemic situation, we additionally controlled for the effects of individual differences in boredom proneness as a predictor of pandemic boredom. Figure 1 summarizes the proposed model and the hypothesized direction of direct and indirect effects. Besides these main hypotheses, we predicted an 


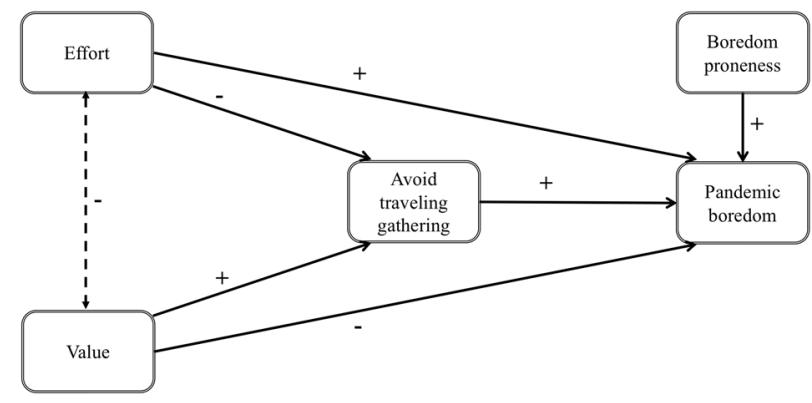

Fig. 1 Conceptual model in which the effect of effort and value on pandemic boredom is mediated by avoiding to travel and to gather.

Avoiding to travel and to gather (situational variables) as well as boredom proneness (personality) predict pandemic boredom. The hypothesized direction of effects is illustrated by $[+]$ and $[-]$ signs.

association between pandemic boredom, boredom proneness, and negative state-like affect. The degree to which countries have been and are still affected by COVID-19 as well as the specific containment measures that they employ vary. Therefore, we additionally aimed to test the proposed model in states with COVID19 restrictions vs. states without COVID-19 restrictions to explore the impact of this dimension on the proposed relationships.

\section{Methods}

Participants. Participants were recruited on December 18th and 19th 2020 from Amazon's website Mechanical Turk (MTurk; requirements: $\geq 50$ HITs, approval rate $\geq 90 \%$, US citizenship). One-thousand five-hundred sixty-six participants completed the online questionnaire for $\$ 1.00$. Thirteen participants $(0.8 \%)$ did not answer at the instructional manipulation check item correctly and were thus removed. The remaining sample comprised 1553 participants $(47.3 \%$ female, $51.7 \%$ male, $1 \%$ other) with an average age of 40.36 years $(S D=12.65)$. The majority of participants reported 13 years or more of education $(86.09 \%)$ and was either working full-time (56.15\%) or self-employed (13.46\%).

A sample size of 1500 participants was targeted to allow recruitment of participants from all the US states and thus assure participation of individuals living in US states with official COVID-19 restrictions and in US states without official restrictions. All US states were represented in the sample, with most participants coming from California (138 participants, 8.89\%), followed by Florida (115 participants, 7.41\%), Texas (106 participants, 6.83\%), and New York (94 participants, 6.05\%). The local ethics committee approved the study, which was conducted in accordance with the Declaration of Helsinki. All participants gave their written informed consent prior to their inclusion in the study.

Procedure and materials. Participants completed the study online, using the Qualtrics Survey Software (https:// www.qualtrics.com). The full study is available on OSF (https:// osf.io/4sje6/). After giving informed consent, participants confirmed to be at least 21 years of age and completed an instructional manipulation check. Next, participants worked on the retrospective questions regarding the thanksgiving holidays, followed by the prospective questions regarding the winter holidays. Finally, participants worked on three personality questionnaires and provided their demographic information (income, education, employment, gender, age). After presenting the personality questionnaires, we additionally included three self-control single items. The data obtained from the personality questionnaires and the three single items were not considered in the context of this study. We used 5-point Likert scales unless otherwise reported $(1=$ strongly disagree, $5=$ strongly agree $)$.

Traveling and gathering over thanksgiving (retrospective) and over the winter holidays (prospective). In the public discourse, restrictions with respect to traveling and gathering to meet people have been highlighted as particularly demanding measures over country-wide holiday periods (Owens and Baker, 2020). Based on a questionnaire of the Harris Poll (Owens and Baker, 2020) we adapted two items to investigate whether participants avoided traveling and gathering with those who do not live in their home over thanksgiving (i.e., "over thanksgiving I avoided traveling" and "over thanksgiving I avoided gathering with those who do not live in my home") and how likely they are to do so for the winter holidays (i.e., "over the winter holidays I will avoid traveling" and "over the winter holidays I will avoid gathering with those who do not live in my home"). Next, it was assessed whether avoiding to travel and to gather was considered valuable over thanksgiving (e.g., "over thanksgiving, avoiding to travel was worth it for me," "over thanksgiving, avoiding to travel was worthwhile for slowing the spread of COVID-19;" see Supplementary information Appendix A for the complete list of items) and whether it will be valuable over the winter holidays (e.g., "avoiding to gather with those who do not live in my home over the upcoming winter holidays will be worth it for me" and "avoiding to gather with those who do not live in my home over the upcoming winter holidays will be worthwhile for slowing the spread of COVID-19;" see Supplementary information Appendix A for the complete list of items). We further investigated whether avoiding to travel and to gather was perceived as effortful over thanksgiving and whether it will be effortful over the winter holidays (e.g., "avoiding to travel over the upcoming winter holidays will require effort from me" and "avoiding to gather with those who do not live in my home over the upcoming winter holidays will require effort from me;" see Supplementary information Appendix A for the complete list of items).

Experience of boredom. To assess the experience of boredom we used three adjectives representing pandemic boredom (i.e., bored, dull, monotonous) taken from the Epistemically-Related Emotion Scales (EES) of Pekrun et al. (2017). These scales are well validated and the focus on understimulation (i.e., dull and monotonous) fits with the current pandemic situation, that might trigger experiences of boredom because of understimulation rather than overstimulation. We additionally included the short form of the Positive and Negative Affect Schedule (Mackinnon et al., 1999), which consists of five positive (i.e., alert, inspired, enthusiastic, excited, determined) and five negative items (i.e., distressed, afraid, nervous, upset, scared). The 13 adjectives (regarding boredom, positive affect, and negative affect) were presented in random order. The exact instructions for evaluating the emotional experience over thanksgiving and over the winter holidays read as follows: "We are interested in your emotional experience over thanksgiving. For each emotion, please indicate the extent you felt this way over thanksgiving" and "We are interested in your forecasted emotional experience over the upcoming winter holidays. For each emotion, please indicate the extent you will feel this way over the upcoming winter holidays." Five-point Likert scales $(1=$ very slightly or not at all, $5=$ extremely) were used.

Subjective perception of restrictions. Then the subjective perception of COVID-19 restrictions was assessed with four items (i.e., "Do the current regional COVID-19 restrictions permit that you travel over the winter holidays" and "Do the current regional COVID19 restrictions permit that you gather with those who do not live 
in your home over the winter holidays;" see Supplementary information Appendix A for the complete list of items). To facilitate interpretation of results, these items were reverse coded (the higher the values, the higher the perceived restrictions).

Boredom proneness. We administered the Boredom Proneness Scale-Short Form (Struk et al., 2017), which is a short questionnaire used to investigate trait boredom ( 8 items, e.g., "I often find myself at 'loose ends,' not knowing what to do"). Mean response scores for this personality variable were computed.

\section{Results}

We report structural equation modeling in order to investigate the determinants of pandemic boredom over the thanksgiving holidays (retrospective) and over the winter holidays (prospective). In these analyses we included effort, value, avoid traveling and gathering, boredom proneness as well as pandemic boredom in aggregated form. Reliability analyses are reported below. Moreover, we computed a multigroup analysis, to compare US states with COVID-19 restrictions and US states without restrictions. To categorize the US states, we resorted to information from webpages usually taken into account by US citizens-i.e., Gale (2020a) for thanksgiving, published on 16.11.2020, and Gale (2020b) for the winter holidays, published on 21.12.2020. When the webpage stated "no restriction" the state was considered as a state without restrictions. All other states were coded as states with restrictions. Four individuals of the total sample did not report their state (remaining sample of $N=1549$ ). Over thanksgiving 907 individuals (58.4\%) were living in an US state with restrictions and over the winter holidays it was 818 individuals that were living in a state with restrictions (52.8\%). The analyses were computed with $R$ (R core Team 2020) with the functionalities of the lavaan package (Rosseel, 2018). The $\mathrm{R}$ code to reproduce the analyses as well as the data set is available on OSF at https://osf.io/4sje6/.

The variables effort, value, avoid traveling and gathering, pandemic boredom, positive affect, negative affect, and subjective restrictions were created by aggregating items across traveling and gathering (but separately for thanksgiving and the winter holidays). In addition, the variable boredom proneness was computed. The internal consistency of the variables was good to very good (see Table 1). The correlations between the variables are reported in Table 2.

Compliance with the recommended behaviors was high (mean of 4.19 out of 5 over thanksgiving and mean of 4.04 out of 5 over the winter holidays). The perceived value of recommended behaviors was in a similar range (mean of 4.08 out of 5 over thanksgiving and mean of 4.00 out of 5 over the winter holidays) whereas exerted effort was medium (mean of 2.70 out of 5 over thanksgiving and mean of 2.90 out of 5 over the winter holidays). The experience of boredom over thanksgiving as well as the forecasted experience of boredom over the winter holidays were relatively low (mean of 1.95 out of 5 over thanksgiving and mean of 1.88 out of 5 over the winter holidays). As expected, the experience of boredom turned out to be aversive. Indeed, pandemic boredom was strongly positively correlated with negative affect (over thanksgiving $r=0.428$ and over the winter holidays $r=0.482$ ) and negatively with positive affect (over thanksgiving $r=-0.279$ and over the winter holidays $r=-0.288$ ).

Table 1 Descriptive summary of measures.

\begin{tabular}{|c|c|c|c|c|c|c|c|}
\hline & Measure & Mean (SD) & Alpha & & Measure & Mean (SD) & Alpha \\
\hline \multirow[t]{7}{*}{ Thanksgiving } & Avoid (2) & $4.192(1.187)$ & 0.779 & Winter holidays & Avoid (2) & $4.043(1.250)$ & 0.843 \\
\hline & Effort (2) & $2.700(1.324)$ & 0.777 & & Effort (2) & $2.901(1.428)$ & 0.864 \\
\hline & Value (4) & $4.081(1.128)$ & 0.935 & & Value (4) & 4.004 (1.201) & 0.950 \\
\hline & Boredom (3) & $1.946(0.980)$ & 0.862 & & Boredom (3) & 1.875 (1.008) & 0.901 \\
\hline & Neg. affect (5) & $1.564(0.794)$ & 0.901 & & Neg. affect (5) & 1.606 (0.809) & 0.905 \\
\hline & Pos. affect (5) & $2.515(0.972)$ & 0.835 & & Pos. affect (5) & $2.648(1.016)$ & 0.849 \\
\hline & Restr. subj. (2) & $3.223(1.358)$ & 0.901 & & Restr. subj. (2) & $3.223(1.363)$ & 0.931 \\
\hline Trait & Boredom (8) & $2.226(0.928)$ & 0.911 & & & & \\
\hline
\end{tabular}

Table 2 Correlations.

\begin{tabular}{|c|c|c|c|c|c|c|c|c|c|}
\hline & $\begin{array}{l}\text { Restrictions } \\
\text { (objective) }\end{array}$ & $\begin{array}{l}\text { Restrictions } \\
\text { (subjective) }\end{array}$ & Value & Effort & Avoid & $\begin{array}{l}\text { Boredom } \\
\text { (state) }\end{array}$ & Negative affect & Positive affect & $\begin{array}{l}\text { Boredom } \\
\text { (trait) }\end{array}$ \\
\hline $\begin{array}{l}\text { Restrictions } \\
\text { (objective) }\end{array}$ & - & $0.178^{\star \star \star}$ & $0.085^{\star \star \star}$ & 0.034 & $0.052^{\star}$ & $0.056^{\star}$ & $0.056^{\star}$ & -0.029 & $0.078^{\star \star}$ \\
\hline $\begin{array}{l}\text { Restrictions } \\
\text { (subjective) }\end{array}$ & $0.207^{\star \star \star}$ & - & $0.068^{\star}$ & -0.010 & $0.087^{\star \star \star}$ & -0.012 & -0.024 & -0.019 & -0.026 \\
\hline Value & $0.095^{\star \star \star}$ & $0.090^{\star \star \star}$ & - & -0.033 & $0.742^{\star \star \star}$ & $0.086^{\star \star \star}$ & 0.025 & -0.032 & $-0.066^{\star}$ \\
\hline Effort & 0.012 & -0.049 & $-0.092^{\star \star \star}$ & - & $-0.052^{\star}$ & $0.149^{\star \star \star}$ & $0.289^{\star \star \star}$ & $0.078^{\star \star}$ & $0.078^{\star \star}$ \\
\hline Avoid & $0.101^{\star \star \star}$ & $0.112^{\star \star \star}$ & $0.795^{\star \star \star}$ & $-0.131^{\star \star \star}$ & - & $0.184^{\star \star \star}$ & 0.017 & $-0.129^{\star \star \star}$ & -0.035 \\
\hline $\begin{array}{l}\text { Boredom } \\
\text { (state) }\end{array}$ & $0.106^{\star \star \star}$ & -0.009 & $0.102^{\star \star \star}$ & $0.127^{\star \star \star}$ & $0.204^{\star \star \star}$ & - & $0.428^{\star \star \star}$ & $-0.279^{\star \star \star}$ & $0.388^{\star \star \star}$ \\
\hline Negative affect & $0.097^{\star \star \star}$ & -0.014 & $0.083^{\star \star}$ & $0.280^{\star \star \star}$ & $0.074^{\star \star}$ & $0.482^{\star \star \star}$ & - & 0.013 & $0.331^{\star \star \star}$ \\
\hline Positive affect & $-0.078^{\star \star}$ & -0.038 & $-0.064^{\star}$ & $0.058^{\star}$ & $-0.173^{\star \star \star}$ & $-0.288^{\star \star \star}$ & -0.030 & - & $-0.242^{\star \star \star}$ \\
\hline $\begin{array}{l}\text { Boredom } \\
\text { (trait) }\end{array}$ & $0.084^{\star \star \star}$ & -0.043 & $-0.070^{\star \star}$ & $0.068^{\star \star}$ & -0.020 & $0.395^{\star \star \star}$ & $0.344^{\star \star \star}$ & $-0.265^{\star \star \star}$ & - \\
\hline
\end{tabular}


Negative and positive affect did not correlate, which is in agreement with the orthogonality of the two subscales in Watson, Clark and Tellegen's two-factorial model (1988).

Note that the positive affect over thanksgiving as well as the forecasted positive affect over the winter holidays was medium (mean of 2.52 out of 5 over thanksgiving and mean of 2.65 out of 5 over the winter holidays), whereas the negative affect was rather low (mean of 1.57 out of 5 over thanksgiving and mean of 1.61 out of 5 over the winter holidays).

Objective restrictions (coded as 0 for US states without restrictions) was positively associated with subjective restrictions (higher values on this scale reflects restrictions) both over thanksgiving $(r=0.178)$ and the winter holidays $(r=0.207)$. These associations illustrate that official restrictions were taken into account; however, the large amount of unexplained variance suggests that other factors also contribute to the perceived restrictions.

Table 2 further shows correlations between our predictor, mediator, and outcome variables. The correlations were in the expected direction, and stronger in the prospective context (winter holidays) when compared to the retrospective context (thanksgiving). Strong associations were revealed between the variables value and avoid traveling and gathering $(r=0.742$ over thanksgiving and $r=0.795$ over the winter holidays). Medium correlations were observed between pandemic boredom and boredom proneness $(r=0.388$ over thanksgiving and $r=0.395$ over the winter holidays), as well as between negative affect and boredom proneness $(r=0.331$ over thanksgiving and $r=0.344$ over the winter holidays).

Retrospective thanksgiving model. The unstandardized path coefficients, standard errors, and $p$-values of the thanksgiving model can be found in Table 3 and are depicted in Fig. 2. Individual differences in perceived value had a weak direct influence on boredom, $b=-0.071, \beta=-0.082, S E=0.031, p=0.021$. Likewise, effort had a weak direct effect on boredom, $b=0.096$, $\beta=0.130, S E=0.018, p<0.001$. That is, the less avoiding to travel and to gather was perceived as valuable and the more it was perceived as effortful, the more boredom was experienced over thanksgiving. These direct effects are in line with the conceptualization of boredom as being characteristic of situations that are low in value and effortful to maintain.

Turning to the indirect effects, we observed that avoiding to travel and to gather were strongly positively influenced by their

\begin{tabular}{|c|c|c|c|c|c|c|}
\hline & \multicolumn{3}{|c|}{ Avoid (Mediator) } & \multicolumn{3}{|c|}{ Pandemic boredom } \\
\hline & Coeff. & SE & $p$ & Coeff. & SE & $p$ \\
\hline Effort & -0.025 & 0.014 & 0.088 & 0.096 & 0.018 & $<0.0001$ \\
\hline Value & 0.780 & 0.024 & $<0.001$ & -0.071 & 0.031 & 0.021 \\
\hline $\begin{array}{l}\text { Boredom } \\
\text { (trait) }\end{array}$ & - & - & - & 0.403 & 0.026 & $<0.001$ \\
\hline $\begin{array}{l}\text { Avoid } \\
R^{2}\end{array}$ & $\begin{array}{c}- \\
55.2 \%\end{array}$ & - & - & $\begin{array}{c}0.219 \\
20.5 \%\end{array}$ & 0.028 & $<0.001$ \\
\hline $\begin{array}{l}\text { Test } \\
\text { statistic }\end{array}$ & \multicolumn{6}{|c|}{$\chi^{2}(3)=16.640, p=0.001$} \\
\hline RMSEA & \multicolumn{6}{|c|}{$0.054,90 \% \mathrm{Cl}[0.031,0.081], p=0.346$} \\
\hline SRMR & \multicolumn{6}{|l|}{0.030} \\
\hline $\mathrm{CFI}$ & \multicolumn{6}{|l|}{0.992} \\
\hline TLI & \multicolumn{6}{|l|}{0.972} \\
\hline
\end{tabular}

All coefficients are unstandardized. Standard errors (SE) were computed with bias-corrected bootstrap method (1000 bootstrap repetitions). $N=1553$. perceived value, $b=0.780, \beta=0.742, S E=0.024, p=<0.001$. However, effort was not a significant predictor, $b=-0.025$, $\beta=-0.027, S E=0.014, p=0.088$, although the direction of the effect was as expected. Avoiding to travel and to gather in turn had the expected positive impact on boredom, $b=0.219$, $\beta=0.266, S E=0.028, p=<0.001$. The resulting indirect effect of value on boredom, $b=0.171, \beta=0.197, S E=0.023$, $p=<0.001$, was significant, whereas the indirect effect of effort on boredom was not, $b=-0.005, \beta=-0.007, S E=0.003$, $p=0.104$. These results were obtained while accounting for the moderate association between boredom proneness and pandemic boredom, $b=0.403, \beta=0.382, S E=0.026, p=<0.001$. In other words, boredom was predicted by the value and effort associated with containment measures over and beyond stable interindividual differences in boredom proneness. The total effect of value on boredom, $b=0.100, \beta=0.115, S E=0.020, p=<0.001$, was significant, as well as the total effect of effort on boredom, $b=0.091, \beta=0.123, S E=0.018, p=<0.001$. The model fitted the data very well, RSMEA $=0.054, \mathrm{SRMR}=0.030, \mathrm{CFI}=0.992$, $\mathrm{TLI}=0.972$. The model explained $55.2 \%$ of variance in the variable avoid traveling and gathering and $20.5 \%$ of variance in the variable pandemic boredom.

Thanksgiving model adjusted for age and gender. We additionally estimated the model including age and gender. Age had a small significant impact on avoid traveling and gathering, $b=0.004$, $\beta=0.044, S E=0.002, p=0.004$ but not on the experience of boredom $(p=0.725)$. Gender had no impact on both variables $(p>0.396)$. Accounting for age and gender did not change the other results (no change in accepting or rejecting the null hypotheses).

Objective restrictions. Next the same model was fitted separately for US states with COVID-19 restrictions and US states without restrictions (multigroup analysis). The regression coefficients and summary information are reported in Table 4 . The results turned out to be highly similar between groups. The only change in statistical significance pertains to the direct effect of value on pandemic boredom, which turned out to be non-significant in the US states without restrictions $(p=0.386)$. The model fitted the data very well, $\mathrm{RSMEA}=0.062, \mathrm{SRMR}=0.030, \mathrm{CFI}=0.989$, $\mathrm{TLI}=0.964$. The descriptive summary of measures between groups is reported in Supplementary information Appendix B (Table B1).

Prospective winter holidays model. The unstandardized path coefficients, standard errors, and $p$-values of the winter holidays model are reported in Table 5 and are depicted in Fig. 3. The results are highly similar to the thanksgiving model. In the winter

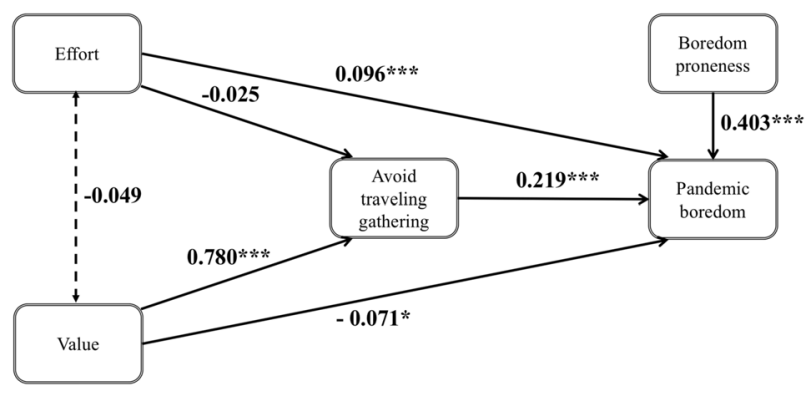

Fig. 2 Thanksgiving model. Coefficients are unstandardized. ${ }^{\star \star \star}$ Difference is significant at the 0.001 level (two-tailed) and ${ }^{*}$ Difference is significant at the 0.05 level (two-tailed). $N=1553$. 
Table 4 Regression coefficients, standard errors, and summary information for the thanksgiving model fitted in US states with restrictions and US states without restrictions (multigroup analysis).

\begin{tabular}{|c|c|c|c|c|c|c|}
\hline & \multicolumn{3}{|c|}{ Avoid (Mediator) } & \multicolumn{3}{|c|}{ Pandemic boredom } \\
\hline Effort, US states with restrictions & -0.010 & 0.017 & 0.544 & 0.114 & 0.022 & $<0.0001$ \\
\hline Value, US states with restrictions & 0.830 & 0.031 & $<0.001$ & -0.103 & 0.045 & 0.022 \\
\hline Value, US states without restrictions & 0.723 & 0.038 & $<0.001$ & -0.040 & 0.046 & 0.386 \\
\hline Boredom (trait), US states with restrictions & - & - & - & 0.404 & 0.033 & $<0.001$ \\
\hline Avoid, US states without restrictions & - & - & 0.215 & 0.044 & $<0.001$ & \\
\hline$R^{2}$, US states with restrictions & $58.7 \%$ & & & $20.6 \%$ & & \\
\hline$R^{2}$, US states without restrictions & $51.1 \%$ & & & $19.8 \%$ & & \\
\hline Test statistic & \multicolumn{6}{|c|}{$\chi^{2}(6)=23.770, p<.001$} \\
\hline RMSEA & \multicolumn{6}{|c|}{$0.062,90 \% \mathrm{Cl}[0.037,0.089], p=0.197$} \\
\hline SRMR & \multicolumn{6}{|c|}{0.030} \\
\hline $\mathrm{CFI}$ & \multicolumn{6}{|l|}{0.989} \\
\hline
\end{tabular}

\begin{tabular}{|c|c|c|c|c|c|c|}
\hline & \multicolumn{3}{|c|}{ Avoid (Mediator) } & \multicolumn{3}{|c|}{ Pandemic boredom } \\
\hline & Coeff. & SE & $p$ & Coeff. & SE & $p$ \\
\hline Effort & -0.051 & 0.013 & $<0.001$ & 0.093 & 0.017 & $<0.0001$ \\
\hline Value & 0.821 & 0.021 & $<0.001$ & -0.093 & 0.034 & 0.006 \\
\hline $\begin{array}{l}\text { Boredom } \\
\text { (trait) }\end{array}$ & - & - & - & 0.418 & 0.028 & $<0.001$ \\
\hline $\begin{array}{l}\text { Avoid } \\
R^{2}\end{array}$ & $\begin{array}{c}- \\
63.6 \%\end{array}$ & - & - & $\begin{array}{l}0.256 \\
21.6 \%\end{array}$ & 0.032 & $<0.001$ \\
\hline $\begin{array}{l}\text { Test } \\
\text { statistic }\end{array}$ & \multicolumn{6}{|c|}{$\chi^{2}(3)=20.124, p<0.001$} \\
\hline RMSEA & \multicolumn{6}{|c|}{$0.061,90 \% \mathrm{Cl}[0.037,0.087], p=0.207$} \\
\hline SRMR & \multicolumn{6}{|c|}{0.028} \\
\hline CFI & \multicolumn{6}{|l|}{0.991} \\
\hline TLI & \multicolumn{6}{|l|}{0.971} \\
\hline
\end{tabular}

All coefficients are unstandardized. Standard errors (SE) were computed with bias-corrected bootstrap method (1000 bootstrap repetitions). $N=1553$.

holiday model, the effects were slightly stronger, and all paths turned out to be significant. Individual differences in perceived value weakly influenced the forecasted experience of boredom during the upcoming winter holidays, $b=-0.093, \beta=-0.112$, $S E=0.034, p=0.006$. Likewise, effort directly but weakly affected the experience of boredom, $b=0.093, \beta=0.133, S E=0.017$, $p=<0.001$. That is, the less individuals valued to avoid traveling and gathering during the winter holidays and the more effortful they expected it to be, the higher the forecasted boredom. Therefore, the direct effects are once more in line with the conceptualization of boredom as being characteristic of situations that are low in value and effortful to maintain.

Turning to the indirect effects, we found that the intention to avoid traveling and gathering was strongly positively related to its value, $b=0.821, \beta=0.790, S E=0.021, p=<0.001$, and weakly negatively to its perceived effort, $b=-0.051, \beta=-0.058$, $S E=0.013, p<0.001$. Moreover, the intention to avoid traveling and gathering also had a small positive impact on pandemic

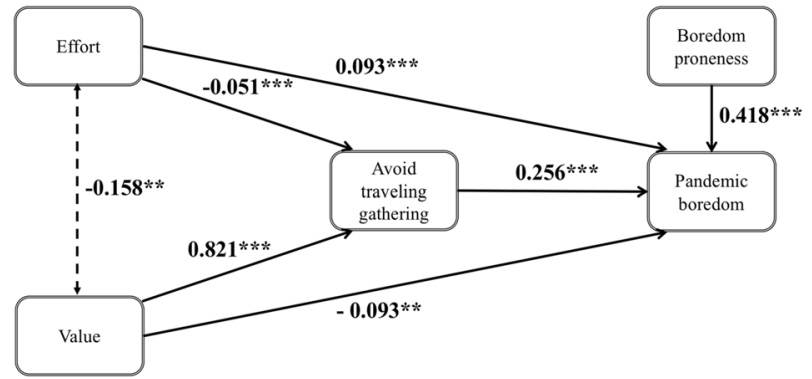

Fig. 3 Winter holidays model. Coefficients are unstandardized. ${ }^{\star \star \star}$ Difference is significant at the 0.001 level (two-tailed) and ${ }^{\star \star}$ Difference is significant at the 0.01 level (two-tailed). $N=1553$.

boredom, $b=0.256, \beta=0.319, S E=0.032, \quad p=<0.001$. The resulting indirect effects of value on boredom, $b=0.210$, $\beta=0.252, S E=0.026, p=<0.001$, and of effort on boredom, $b=-0.013, \beta=-0.018, S E=0.004, p=0.001$, both turned out to be significant. These results were obtained while accounting for the moderate association between boredom proneness and pandemic boredom, $\quad b=0.418, \quad \beta=0.386, \quad S E=0.028$, $p=<0.001$. Accordingly, the forecasted pandemic boredom during the winter holidays was predicted by the expected value and effort of the containment measures over and beyond stable interindividual differences in boredom. The total effect of value on boredom, $b=0.117, \beta=0.140, S E=0.019, p=<0.001$, was significant, as well as the total effect of effort on boredom, $b=0.080, \beta=0.114, S E=0.018, p=<0.001$. The model fitted the data very well, RSMEA $=0.061, \mathrm{SRMR}=0.028, \mathrm{CFI}=0.991$, $\mathrm{TLI}=0.971$. The model explained $63.6 \%$ of variance in the variable avoid traveling and gathering and $21.6 \%$ of variance in the variable pandemic boredom.

Winter holidays model adjusted for age and gender. We additionally estimated the model including age and gender. Both predictors turned out to be non-significant $(p>0.237)$ and they did not change the other results (no change in accepting or rejecting the null hypotheses). 
Table 6 Regression coefficients, standard errors, and summary information for the winter holidays model fitted in US states with restrictions and US states without restrictions (multigroup analysis).

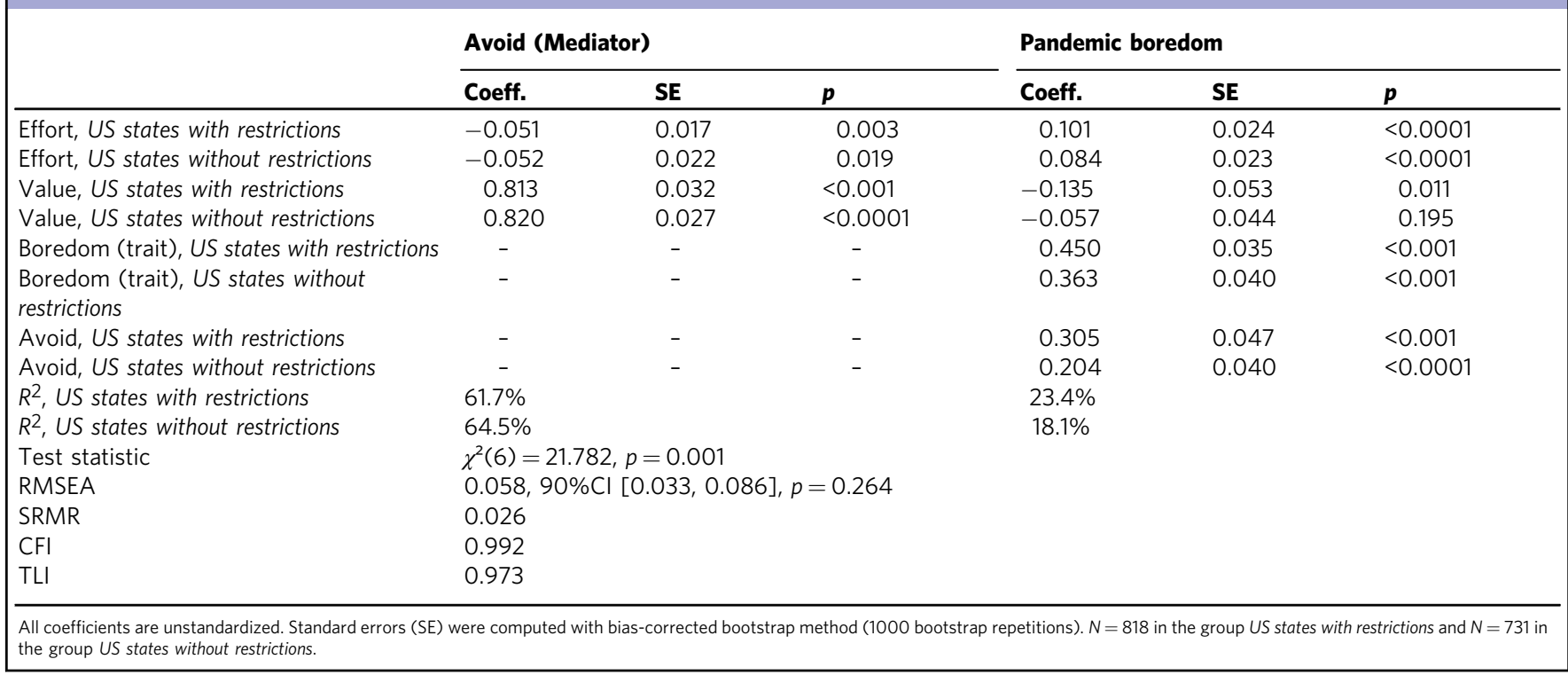

Objective restrictions. The same model was fitted in US states with COVID-19 restrictions and US states without restrictions (multigroup analysis). The regression coefficients and summary information are reported in Table 6. The results turned out to be highly similar between groups. Again, the only change in statistical significance pertains the direct effect of value on boredom pandemic, which turned out to be non-significant in the US states without restrictions $(p=0.195)$. The model fitted the data very well, RSMEA $=0.058, \mathrm{SRMR}=0.026, \mathrm{CFI}=0.992, \mathrm{TLI}=0.973$. The descriptive summary of measures between groups is reported in Supplementary information Appendix B (Table B2).

\section{Discussion}

We investigated the cognitive and behavioral mechanisms that underlie pandemic boredom. Besides examining the effect of behavioral compliance with COVID-19 recommendations on boredom, we were particularly interested in teasing apart the direct and indirect effects of the value and effort ascribed to following these recommendations on the experience of boredom. In line with current theorizing on pandemic boredom (Martarelli and Wolff, 2020) higher retrospective and prospective compliance with behavioral recommendations predicted more boredom. In other words, individuals who bothered to comply with the behavioral recommendations experienced higher levels of boredom than individuals who did not bother.

Moreover, we found that direct and indirect effects of value and effort on boredom went into opposite directions. Higher value had negative direct effects on boredom (perceiving measures as being valuable $\rightarrow$ lower boredom) but also positive indirect effects (higher value $\rightarrow$ higher compliance $\rightarrow$ higher boredom). The total effects of value on boredom were positive, suggesting that, overall, higher value led to more boredom by facilitating compliance with behavioral restrictions. The inverse pattern of results emerged for effort: We found a positive direct impact on boredom (perceiving adherence as effortful $\rightarrow$ higher boredom) but a negative indirect impact (higher effort $\rightarrow$ lower compliance $\rightarrow$ lower boredom). The total effect of effort on boredom was positive, suggesting that, overall, higher effort led to more boredom directly rather than by changing behavior. These results underline that the socially desired behavior of bothering to follow government recommendations during COVID -19 comes at the individual cost of increased boredom, which is an aversive experience and strongly linked with negative affect. Crucially, these findings also highlight that increasing perceived value of containment measures might be psychologically demanding if people are void of strategies to cope with the boredom resulting from adherence. In contrast, reducing the effort ascribed to behavioral restrictions not only increases adherence but also leads to less boredom.

Beyond these main findings, at least three other findings warrant further discussion. First, the effects of value and effort on reported behavior differed substantially with respect to their magnitude; second, boredom proneness affected pandemic boredom, attesting to the importance of individual difference variables in understanding behavior during the pandemic; and third, the overall pattern of results was independent of the objective pandemic-imposed restrictions and robust for forecasted and retrospective behavior and experiences alike. We discuss these three points below.

First, when considering the impact of value and effort on recommended behaviors (first part of the proposed mediation model), the results revealed a more potent role of value for behavior (see for example Frömer et al., 2021). Individuals are more likely to restrict their behavior if they value this choice. Effort played a smaller but still significant role in the models reported here. It is possible that the effect of effort on recommended behaviors turned out to be small due to structural relationships between value and effort: The value of engaging with behavioral recommendations was on average high and accompanied by a willingness to invest effort. In line with this, theoretical work proposes that ascribing high value to an action might reduce the effort that is felt when engaging in this action (Székely and Michael, 2020).

Second, when it comes to trait-like boredom proneness, the results revealed an impact of this stable personality dimension on the experience of boredom. Boredom proneness significantly predicted pandemic boredom and the effect was even stronger than the effect of actual behavior (avoid traveling and gathering) on pandemic boredom, corroborating existing research that shows a relation between state and trait measures of boredom (Mercer-Lynn et al., 2014). Our results illustrate that boredom prone individuals are especially vulnerable, because they experience higher levels of pandemic boredom (Tam et al., 2021). This is in line with previous research that has found a robust link 
between high trait boredom and less adherence to COVID-19 containment measures (Bieleke et al., 2021; Boylan et al., 2020; Wolff et al., 2020). This finding was also replicated in a recent high-powered cross-national study of Westgate et al. (2021); however, this longitudinal study also provided evidence that other variables than boredom proneness might be the drivers of adherence. Therefore, the causality of the relationship between boredom proneness and adherence remains an open question that requires other methodological approaches than those previously used in the literature.

Third, the models estimated for the different contexts (thanksgiving, winter holidays, US states without restrictions, US states with restrictions) yielded highly similar results, speaking to the robustness and generalizability of our findings. The only difference pertained to the direct effect of value on the experience of boredom, which turned out to be significant in the US states with restrictions but not in the US states without restrictions. That said, this particular direct effect was small in all models, meaning that the difference could be a statistical artifact (e.g., larger standard errors). Apart from this difference, the multigroup analysis revealed similar structural relationships among the investigated variables in the US states with vs. without COVID-19 restrictions. Despite the rules in force in each state, there is a general agreement of recommended behaviors in the US (beyond the states). This common discourse about recommendations might have homogenized the perceptions and behaviors of individuals in the different states with different rules. We found a small relation between objective and subjective restrictions, suggesting that actual COVID-19 restrictions played a surprisingly small role in determining the restrictions the population feels to be in place. In general, compliance with the recommended behaviors was high. Nevertheless, it seems that independent of the specific laws, it is the value that individuals attribute to the recommended behaviors that predominantly determines their behavior.

Our findings have several important implications beyond behavioral and psychological science in that they provide hints for nonpharmaceutical interventions in the current COVID-19 pandemic. One option for governments could be to highlight the value of recommended behaviors. Previous experimental research has identified the incongruence of current activities and one's own goals as main cause of feeling bored (e.g., van Tilburg and Igou, 2013). Further, knowing that other individuals and oneself benefit from the recommended behaviors makes it easier to comply with them (Brooks et al., 2020; Roma et al., 2021; Seale et al., 2020). However, in our study we highlight an important trade-off: Increases in value are accompanied by increases in the experienced boredom (indirect and total effects of value on boredom). This finding suggests that highlighting the value of containment measures might not be sufficient, it might also be crucial to focus on consequences for emotional experience in general and on boredom in particular. Another promising route for governments' interventions could be to reduce the effort needed to comply with behavioral restrictions. For instance, it has been suggested that simple action planning (e.g., what to do when feeling bored) could help people navigate the pandemic by supporting them in dealing with the difficulties of compliance (Bieleke et al., 2021; Thürmer et al., 2021). Our present results suggest that reducing effort has beneficial effects on behavior and simultaneously reduces boredom. As the direct effect of effort on boredom exceeded the indirect effect via behavior, measures that reduce effort should have an unequivocally beneficial effect during the pandemic.

Limitations, future research, and conclusion. Four limitations of the study should be considered when interpreting the findings. First, mediation analyses on cross-sectional data are mostly uninformative about longitudinal causal processes because temporal precedence as well as stability of the effects is not given (e.g., Maxwell and Cole, 2007; Maxwell et al., 2011). Furthermore, our aggregated estimates might only partially reflect individual experiences and behaviors (Fisher et al., 2018; see also Hamaker and Ryan, 2019; Adolf and Fried, 2019). Moreover, the evidence for past and prospective boredom should be interpreted with caution. Empirical work has shown that participants are poor at remembering and predicting their emotional states, particularly because their lay causal theories can influence their answers (Wilson et al., 1989; Wilson and Klaaren, 1992; Klaaren et al., 1994). A final limitation is that we collected data from US MTurk participants, thus results cannot be generalized to other cultures and countries. Socio-cultural variables such as inequalities in access to resources, economic disadvantage, and different rates/ responses to COVID-19 across countries are likely to affect the constructs under investigation here (Westgate and Steidle, 2020; Van Bavel et al., 2020).

To address these limitations, future research should experimentally manipulate value and effort in a between-subjects design with random assignment, which is a necessary condition for mediation analyses of causal effects (MacKinnon, 2008). Yet another possibility to assure temporal precedence are longitudinal studies with sufficient timepoints to partial out between-person from within-person effects in the regression of an outcome on a time-varying covariate (Hamaker et al., 2015). Instead of using retrospective and prospective self-report measures future research might use experience sampling methods and, for example, ask participants to briefly describe momentary emotions when a probe interrupts their current task. Future research might also include samples from other cultures and countries to warrant generalizability of results

Despite these limitations, the present findings underline the importance of considering boredom in the context of a pandemic. The results of prior work suggest that boredom prone individuals are less likely to comply with social distancing guidelines (e.g., Wolff et al., 2020). Here, we demonstrate that complying with behavioral recommendations can be a source of boredom that is not only aversive itself but also linked with negative affect. In addition, and in line with theoretical work on boredom and the regulation of goal-directed behavior (Eastwood et al., 2012; Shenhav et al., 2017; Westgate and Wilson, 2018; Wolff and Martarelli, 2020), by showing that perceptions of value and effort are not only robust predictors of behavior but also of the experience of pandemic boredom, our findings provide insights into the mechanisms that underlie pandemic boredom. We hope that the ideas and findings that we present here will inspire future research on how to improve compliance with containment measures as well as understanding the individual pandemic emotional experiences.

\section{Data availability}

The full study, data, and code for the main analyses are available at https://osf.io/4sje6/.

Received: 1 April 2021; Accepted: 3 September 2021; Published online: 21 September 2021

\section{References}

Adolf JK, Fried EI (2019) Ergodicity is sufficient but not necessary for group-toindividual generalizability. Proc Natl Acad Sci USA 116:6540. https://doi.org/ $10.1073 /$ pnas. 1818675116

Badre D (2021) How we can deal with "pandemic fatigue." https:// www.scientificamerican.com/article/how-we-can-deal-with-pandemic-fatigue/ 
Bench SW, Lench HC (2019) Boredom as a seeking state: boredom prompts the pursuit of novel (even negative) experiences. Emotion 19:242-254. https:// doi.org/10.1037/emo0000433

Bench SW, Lench HC (2013) On the function of boredom. Behav Sci 3:459-472. https://doi.org/10.3390/bs3030459

Bieleke M, Barton L, Wolff W (2021) Trajectories of boredom in self-control demanding tasks. Cogn Emotion https://doi.org/10.1080/02699931.2021.1901656

Bieleke M, Martarelli CS, Wolff W (2021) If-then planning, self-control, and boredom as predictors of adherence to social distancing guidelines: evidence from a two-wave longitudinal study with a behavioral intervention. Curr Psychol https://doi.org/10.1007/s12144-021-02106-7

Bieleke M, Wolff W (2021) It's not a bug, it's boredom: effortful willpower balances exploitation and exploration. Behav Brain Sci 44:e33. https://doi.org/10.1017/ S0140525X20001053

Boylan J, Seli P, Scholer AA, Danckert J (2020) Boredom in the COVID-19 pandemic: trait boredom proneness, the desire to act, and rule-breaking. Person Individ Differ 110387. https://doi.org/10.1016/j.paid.2020.110387

Brooks SK, Webster RK, Smith LE et al. (2020) The psychological impact of quarantine and how to reduce it: rapid review of the evidence. Lancet 395:912-920. https://doi.org/10.1016/S0140-6736(20)30460-8

Danckert J (2019) Boredom: managing the delicate balance between exploration and exploitation. In: Velasco JR (ed) Boredom is in your mind: a shared psychological philosophical approach. Springer.

Danckert J, Mugon J, Struk AA, Eastwood JD (2018) Boredom: what is it good for? In: Lench $H$. (ed) The function of emotions. Springer.

Droit-Volet S, Gil S, Martinelli N et al. (2020) Time and Covid-19 stress in the lockdown situation: time free, "dying" of boredom and sadness. PLoS ONE 15:1-15. https://doi.org/10.1371/journal.pone.0236465

Eastwood JD, Frischen A, Fenske MJ, Smilek D (2012) The unengaged mind: defining boredom in terms of attention. Perspect Psychol Sci 7:482-495. https://doi.org/10.1177/1745691612456044

Ehl D (2021) 6 ways to fight coronavirus lockdown boredom. https://www.dw.com/ en/6-ways-to-fight-coronavirus-lockdown-boredom/a-56394277

Elpidorou A (2021) Is boredom one or many? A functional solution to the problem of heterogeneity. Mind Language 36:491-511. https://doi.org/10.1111/mila.12282

Elpidorou A (2014) The bright side of boredom. Front Psychol 5:1245. https:// doi.org/10.3389/fpsyg.2014.01245

Elpidorou A (2018) The bored mind is a guiding mind: toward a regulatory theory of boredom. Phenomenol Cogn Sci 17:455-484. https://doi.org/10.1007/ s11097-017-9515-1

Fahlman SA, Mercer KB, Gaskovski P et al. (2009) Does a lack of life meaning cause boredom? Results from psychometric, longitudinal, and experimental analyses. J Soc Clin Psychol 28:307-340. https://doi.org/10.1521/jscp.2009.28.3.307

Farmer R, Sundberg ND (1986) Boredom proneness: the development and correlates of a new scale. J Person Assess 50:4-17. https://doi.org/10.1207/ s15327752jpa5001_2. PMID: 3723312

Fisher AJ, Medaglia JD, Jeronimus BF (2018) Lack of group-to-individual generalizability is a threat to human subjects research. Proc Natl Acad Sci 115:E6106-E6115. https://doi.org/10.1073/pnas.1711978115

Frömer R, Lin H, Dean Wolf CK et al. (2021) Expectations of reward and efficacy guide cognitive control allocation. Nat Commun 12:1030. https://doi.org/ $10.1038 / \mathrm{s} 41467-021-21315-\mathrm{z}$

Gale H (2020a) Traveling for Thanksgiving? Here are the states with quarantine rules. https://wlos.com/news/local/traveling-for-thanksgiving-here-are-thestates-with-with-quarantine-rules

Gale H (2020b) Traveling for Christmas? Here are the COVID-19 quarantine, testing rules for each state. https://wpde.com/news/local/traveling-forchristmas-here-are-the-covid-19-quarantine-testing-rules-for-each-state

Hamaker EL, Kuiper RM, Grasman RP (2015) A critique of the cross-lagged panel model. Psychol Method 20:102-116. https://doi.org/10.1037/a0038889

Hamaker EL, Ryan O (2019) A squared standard error is not a measure of individual differences. Proc Natl Acad Sci 116:6544-6545. https://doi.org/ $10.1073 /$ pnas. 1818033116

Klaaren KJ, Hodges SD, Wilson TD (1994) The role of affective expectations in subjective experience and decision-making. Soc Cogn 12:77-101. https:// doi.org/10.1521/soco.1994.12.2.77

Kucharski AJ, Russell TW, Diamond C, et al (2020) Early dynamics of transmission and control of COVID-19: a mathematical modelling study. Lancet Infect Dis https://doi.org/10.1016/S1473-3099(20)30144-4

Kurzban R, Duckworth A, Kable JW, Myers J (2013) An opportunity cost model of subjective effort and task performance. Behav Brain Sci 36:661-679. https:// doi.org/10.1017/S0140525X12003196

Mackinnon A, Jorm AF, Christensen H et al. (1999) A short form of the positive and negative affect schedule: evaluation of factorial validity and invariance across demographic variables in a community sample. Person Individ Differ 27:405-416. https://doi.org/10.1016/S0191-8869(98)00251-7

MacKinnon DP (2008) Introduction to statistical mediation analysis. Erlbaum, Mahwah, NJ
Martarelli CS, Wolff W (2020) Too bored to bother? Boredom as a potential threat to the efficacy of pandemic containment measures. Human Soc Sci Commun 7. https://doi.org/10.1057/s41599-020-0512-6

Maxwell SE, Cole DA (2007) Bias in cross-sectional analyses of longitudinal mediation. Psychol Methods 12:23-44. https://doi.org/10.1037/1082-989X.12.1.23

Maxwell SE, Cole DA, Mitchell MA (2011) Bias in cross-sectional analyses of longitudinal mediation: partial and complete mediation under an autoregressive model. Multivariate Behav Res 46:816-841. https://doi.org/ $10.1080 / 00273171.2011 .606716$

Mercer-Lynn KB, Bar RJ, Eastwood JD (2014) Causes of boredom: the person, the situation, or both? Person Individ Differ 56:122-126. https://doi.org/10.1016/ j.paid.2013.08.034

Owens C, Baker S (2020) 25\%-30\% of Americans say they'll ignore Thanksgiving warning. https://www.axios.com/americans-ignore-thanksgiving-warningharris-poll-d8f8eac1-2a46-46c5-86cf-2802592c0a6d.html)

Pekrun R (2006) The control-value theory of achievement emotions: assumptions, corollaries, and implications for educational research and practice. Educ Psychol Rev 18:315-341. https://doi.org/10.1007/s10648-006-9029-9

Pekrun R, Goetz T, Daniels LM et al. (2010) Boredom in achievement settings: exploring control-value antecedents and performance outcomes of a neglected emotion. J Educ Psychol 102:531-549. https://doi.org/10.1037/ a0019243

Pekrun R, Vogl E, Muis KR, Sinatra GM (2017) Measuring emotions during epistemic activities: the epistemically-related emotion scales. Cogn Emotion 31:1268-1276. https://doi.org/10.1080/02699931.2016.1204989

Prem K, Liu Y, Russell TW, et al (2020) The effect of control strategies to reduce social mixing on outcomes of the COVID-19 epidemic in Wuhan, China: a modelling study. Lancet Public Health https://doi.org/10.1016/S24682667(20)30073-6

R Core Team (2020) R: A language and environment for statistical computing [Computer software]. https://cran.r-project.org/

Roma P, Monaro M, Muzi L, Colasanti M, Ricci E, Biondi S, Napoli C, Ferracuti S, Mazza C (2021) How to improve compliance with protective health measures during the COVID-19 outbreak: testing a moderated mediation model and machine learning algorithms. Int J Environ Res Public Health 17(19):7252. https://doi.org/10.3390/ijerph17197252

Rosseel Y (2018) lavaan: latent variable analysis. https://cran.r-project.org/ package $=$ lavaan.

Seale H, Heywood AE, Leask J, Sheel M, Thomas S, Durrheim DN et al. (2020) COVID-19 is rapidly changing: examining public perceptions and behaviors in response to this evolving pandemic. PLoS ONE 15(6):e0235112. https:// doi.org/10.1371/journal.pone.0235112

Shenhav A, Musslick S, Lieder F et al. (2017) Toward a rational and mechanistic account of mental effort. Ann Rev Neurosci 40:99-124. https://doi.org/ 10.1146/annurev-neuro-072116-031526

Struk AA, Carriere JSA, Cheyne JA, Danckert J (2017) A short boredom proneness scale: development and psychometric properties. Assessment 24:346-359. https://doi.org/10.1177/1073191115609996

Székely M, Michael J (2020) The sense of effort: a cost-benefit theory of the phenomenology of mental effort. Rev Philos Psychol https://doi.org/10.1007/ s13164-020-00512-7

Tam KYY, Tilburg WAP, Chan CS (2021) What is boredom proneness? A comparison of three characterizations. J Person https://doi.org/10.1111/ jopy. 12618

Thürmer JL, Wieber F, Gollwitzer PM (2021) How can we master the 2020 Coronavirus pandemic? The role of planning at social levels. Eur Rev Soc Psychol 0:1-47. https://doi.org/10.1080/10463283.2020.1852699

Van Bavel JJ, Baicker K, Boggio PS et al. (2020) Using social and behavioural science to support COVID-19 pandemic response. Nat Human Behav 4:460-471. https://doi.org/10.1038/s41562-020-0884-z

van Tilburg WAP, Igou ER (2012) On boredom: lack of challenge and meaning as distinct boredom experiences. Motivat Emotion 36:181-194. https://doi.org/ 10.1007/s11031-011-9234-9

van Tilburg WAP, Igou ER (2013) On the meaningfulness of behavior: an expectancy x value approach. Motivat Emotion 37:373-388. https://doi.org/ 10.1007/s11031-012-9316-3

Watson D, Clark LA, Tellegen A (1988) Development and validation of brief measures of positive and negative affect: the PANAS scales. J Person Soc Psychol 54:1063-1070

Westgate EC, Wilson TD (2018) Boring thoughts and bored minds: the MAC model of boredom and cognitive engagement. Psychol Rev 125:689-713. https://doi.org/10.1037/rev0000097

Westgate EC, Steidle B (2020) Lost by definition: Why boredom matters for psychology and society. Soc Personal Psychol Compass. 2020; 14:e12562. https:// doi.org/10.1111/spc3.12562

Westgate EC, Buttrick N, Lin Y, El Helou G et al (2021) Pandemic boredom: predicting boredom and its consequences during self-isolation and quarantine. https://doi.org/10.31234/osf.io/78kma 
Wilson TD, Klaaren KJ (1992) Expectation whirls me round: the role of affective expectations on affective experiences. Rev Personal Soc Psychol 14:1-31. https://doi.org/10.1177/01461672022811002

Wilson TD, Lisle DJ, Kraft D, Wetzel CG (1989) Preferences as expectation-driven inferences: effects of affective expectations on affective experience. J Person Soc Psychol 56:519-530. https://doi.org/10.1037//0022-3514.56.4.519

Wolff W, Martarelli CS (2020) Bored into depletion? Towards a tentative integration of perceived self-control exertion and boredom as guiding signals for goal-directed behavior. Perspect Psychol Sci 15:1272-1283. https://doi.org/ $10.1177 / 1745691620921394$

Wolff W, Martarelli CS, Schüler J, Bieleke M (2020) High boredom proneness and low trait self-control impair adherence to social distancing guidelines during the COVID-19 pandemic. Int J Environ Res Public Health 17:5420. https:// doi.org/10.3390/ijerph17155420

Yan L, Gan Y, Ding X et al. (2021) The relationship between perceived stress and emotional distress during the COVID-19 outbreak: effects of boredom proneness and coping style. J Anxiety Disorder 77:102328. https://doi.org/ 10.1016/j.janxdis.2020.102328

\section{Acknowledgements}

None

\section{Competing interests}

The authors declare no competing interests.

\section{Additional information}

Supplementary information The online version contains supplementary material available at https://doi.org/10.1057/s41599-021-00894-8.

Correspondence and requests for materials should be addressed to Corinna S. Martarelli.

Reprints and permission information is available at http://www.nature.com/reprints

Publisher's note Springer Nature remains neutral with regard to jurisdictional claims in published maps and institutional affiliations.

\begin{abstract}
(c) (i) Open Access This article is licensed under a Creative Commons Attribution 4.0 International License, which permits use, sharing, adaptation, distribution and reproduction in any medium or format, as long as you give appropriate credit to the original author(s) and the source, provide a link to the Creative Commons license, and indicate if changes were made. The images or other third party material in this article are included in the article's Creative Commons license, unless indicated otherwise in a credit line to the material. If material is not included in the article's Creative Commons license and your intended use is not permitted by statutory regulation or exceeds the permitted use, you will need to obtain permission directly from the copyright holder. To view a copy of this license, visit http://creativecommons.org/ licenses/by/4.0/.
\end{abstract}

(C) The Author(s) 2021 